\title{
A Novel UWB Antenna with Reconfigurable Notch Bands
}

\author{
Ritika Sharma, Rajesh Khanna
}

\begin{abstract}
A UWB antenna with reconfigurable notch band characteristics is proposed in this paper. The tunable notches are created using modified $E$ shaped resonators that can be reconfigured to modified $C$ shape; etched on either side of the microstrip feed line of a circular patch $U W B$ antenna. The single and dual band rejection characteristics are created by using $C$ and E shaped structure respectively. Reconfigurability is achieved by using two RF switches. By varying the $\mathrm{ON}$ and $\mathrm{OFF}$ states of the $R F$ switches, two different notch bands are created; single notch band from 4 to $6.2 \mathrm{GHz}$ and an additional notch band from 7.6 to $10 \mathrm{GHz}$ are achieved. These wide bandwidth rejection performance leads to notching of WLAN, WiMAX, C-band frequencies and $X$ band Satellite communication systems.
\end{abstract}

Index Terms: Circular patch antennas, parasitic element, reconfigurable, resonator, $R F$ switch, $U W B$.

\section{INTRODUCTION}

Currently, there is huge interest in ultra wide band applications in wireless communication. In the year 2002 FCC Federal Communication Commission (1) approved the authorization of using $3.1 \mathrm{GHz}$ to $10.6 \mathrm{GHz}$ band for popular communication applications. Narrowband systems, such as WLAN (5.15-5.825 GHz), WiMAX (5.25 to $5.85 \mathrm{GHz}), \mathrm{C}$ band (4-6.2 GHz) and $\mathrm{X}$ band satellite communication systems $(7.6-10 \mathrm{GHz})$ generally interfere with the UWB system. In order to avoid the interference, UWB antennas with band notching characteristics are needed and hence, are frequently used due to their ability to utilize the complete spectrum even in the presence of interfering signals in its close proximity [2-4]. Notch frequencies only reject the disturbances from interfering bands. But these designs lack in utilizing the full UWB coverage.

By utilizing reconfigurable structures, several interfering frequencies can be eliminated at different instances in the UWB antenna [5-7]. Designing of reconfigurable UWB antenna uses require switching between different configuration using p-i-n diodes, SPST RF switches, SPDT RF switches [8-10], and micro-electro-mechanical (MEMS) [5,13-14].

This paper presents a UWB antenna design which has reconfigurable notching characteristics. The circular patch antenna design with partial ground plane achieves ultra-wideband coverage, then modified $\mathrm{C}$ and $\mathrm{E}$ shaped structures have been etched on either sides of microstrip feed

Revised Manuscript Received on July 09, 2019.

Ritika Sharma, Electronics and Communication Department Thapar Institute of engineering and technology Patiala,India.

Rajesh Khanna, Electronics and Communication Department Thapar Institute of engineering and technology Patiala,India. line of circular patch antenna. Reconfiguration is achieved by placing SPST RF switches on the appropriate location which leads to single and dual tunable notch frequencies. When $\mathrm{E}$ shaped resonators are configured, two bands $(4-6.2 \mathrm{GHz}$ and 7.6-10 GHz) are notched and when $\mathrm{C}$ shaped resonators are reconfigured, single $4-6.2 \mathrm{GHz}$ band is notched.

\section{ANTENNA DESIGN AND ANALYSIS}

\section{A. Initial Circular UWB Antenna Design}

The basic antenna design started with consideration of a circular patch having patch radius $8.6 \mathrm{~mm}$ and partial ground has dimensions of $30 \mathrm{~mm} \times 11 \mathrm{~mm}$. Fig. 1(a-b) presents the front and back view of basic antenna design. Microstrip Antenna with partial ground plane gives a higher bandwidth and improved impedance matching [12]. The antenna is designed on FR4 substrate material (relative permittivity $\mathrm{Er}=$ 4.4) having size $30 \times 30 \times 1.6 \mathrm{~mm}^{3}$. The dimensions of the basic UWB antenna design after optimization are as follows: $L_{s}=30 \mathrm{~mm}, W_{s}=30 \mathrm{~mm}, W_{f}=1.4 \mathrm{~mm}, L_{f}=11.9 \mathrm{~mm}, L g=11$ $\mathrm{mm}$. The width of the feed line $W_{f}$ is determined using [11] to have $50-\Omega$ impedance. After simulating and optimizing antenna configuration with partial ground the fractional bandwidth of UWB antenna is found to be $120.9 \%$ (3.2 to $13 \mathrm{GHz}$ ) as shown in fig. 2.
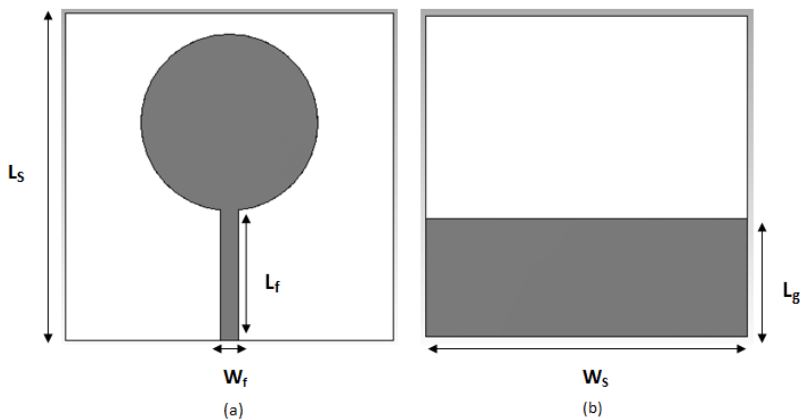

Fig. 1 Basic UWB Antenna Structure (a) front and (b) back view

\section{B. UWB Antenna with Dual Notch band}

Next we created band-notched characteristics in initial UWB antenna, to overcome the interferences within the band of UWB antenna. The proposed modified UWB antenna is presented in Fig. 3a. It composed of two symmetric modified E shaped parasitically coupled resonators placed besides the microstrip feed line as shown in fig. $3 b$ in its expanded view. The dimensions of the E shaped resonator are given in Table I. The simulated return loss of modified UWB antenna is shown in the fig. 4 where one notch band is from 4 to $6.2 \mathrm{GHz}$ and second notch band is from 7.6 to $10 \mathrm{GHz}$.

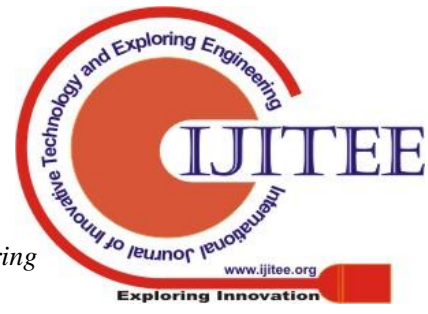


Table 1 Dimensions of Figure 3(b).

\begin{tabular}{cc}
\hline \hline Parameters & Dimension $(\mathrm{mm})$ \\
\hline L1 & 5.6 \\
L2 & 4.1 \\
L3 & 1.3 \\
L4 & 1.8 \\
L5 & 2 \\
L6 & 4.8 \\
\hline \hline
\end{tabular}

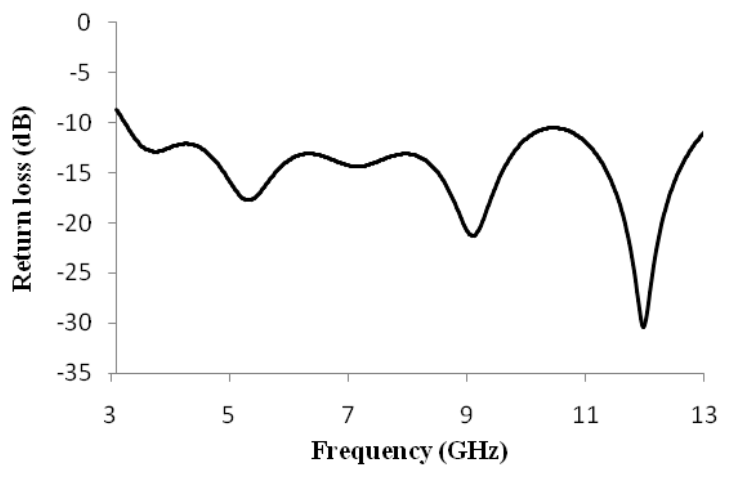

Fig. 2 Simulated return loss plot of basic UWB Antenna Structure.

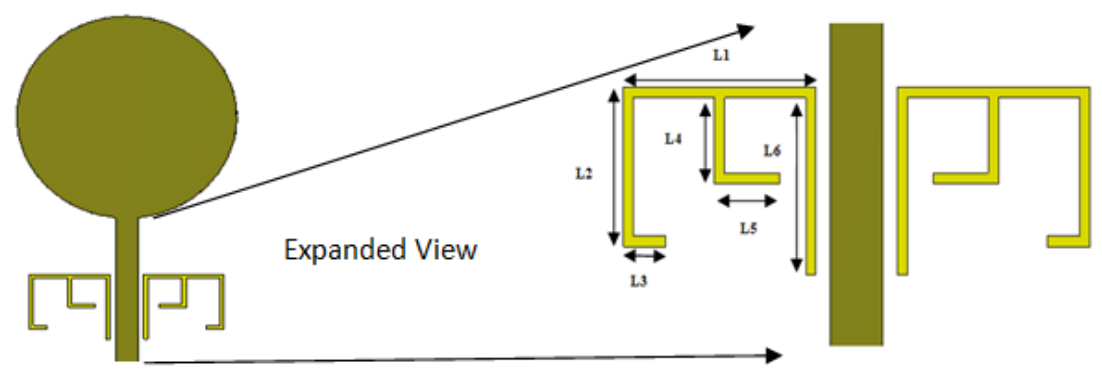

(a)

(b)

Fig. 3(a) Modified UWB antenna and (b) its expanded view.

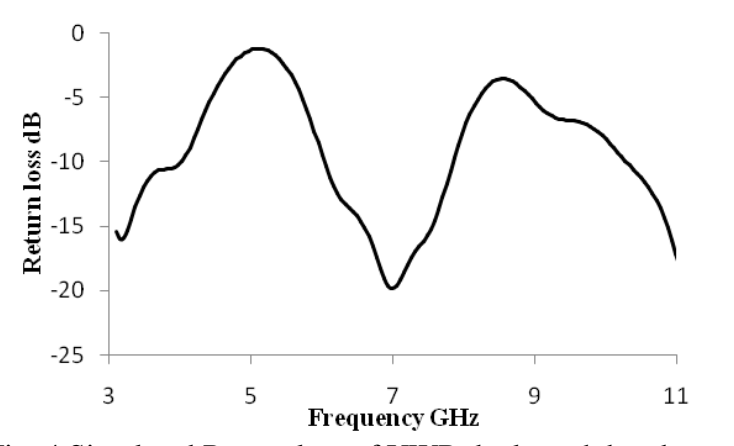

Fig. 4 Simulated Return loss of UWB dual notch band antenna.

\section{Parametric STUDY OF DUAL NOTCH ANTENNA}

The lengths of the resonator significantly affect the notched frequency. That is, increase in the lengths of the resonator, shifts the notch bands in the direction of lower frequency, as inductance and capacitance effects are reduced. The notch frequency is stated below

$$
f_{\text {notch }}=\frac{c}{\sqrt{\varepsilon_{\text {eff }}}}
$$

where, $\varepsilon_{\text {eff }}$ and $L$ are the effective dielectric constant and the total length of the resonator and the speed of light in space, respectively. In parametric study one parameter is varied for studying its effects on return loss while fixing others to their optimum values. The optimum values are as shown in the Table 1. The return loss characteristics with variations in the resonator dimension parameters are exhibited in Fig. $5(\mathrm{a})-(\mathrm{g})$.

\section{A. Effect of Variation of length L1 on return loss}

The value of $\mathrm{L} 1$ is varied from $4.5 \mathrm{~mm}$ to $6.5 \mathrm{~mm}$ in a step of $1 \mathrm{~mm}$. The optimum value of $\mathrm{L} 1$ is found to be $5.5 \mathrm{~mm}$ where one notch band is from 4 to $6.2 \mathrm{GHz}$ and second notch band is from 7.6 to $10 \mathrm{GHz}$. Increasing the length L1 of resonator to $6.5 \mathrm{~mm}$, the first notch band gets shifted from 3.7 to $5.6 \mathrm{GHz}$ and second band gets shifted from 7.2 to $9.7 \mathrm{GHz}$. Similarly decreasing the length L1 to $4.5 \mathrm{~mm}$ shifts the lower notch band from 4.2 to $6.5 \mathrm{GHz}$ and 8 to $9.8 \mathrm{GHz}$. These variations are shown in fig. 5(a).

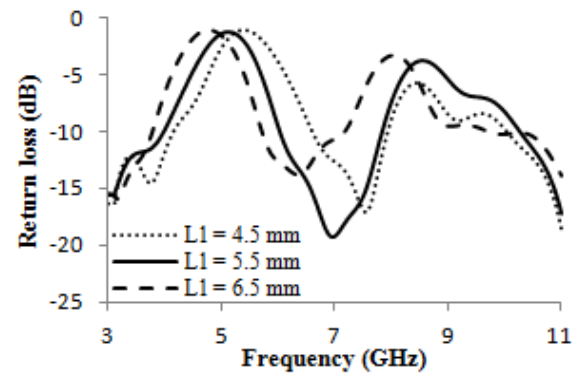

(a)

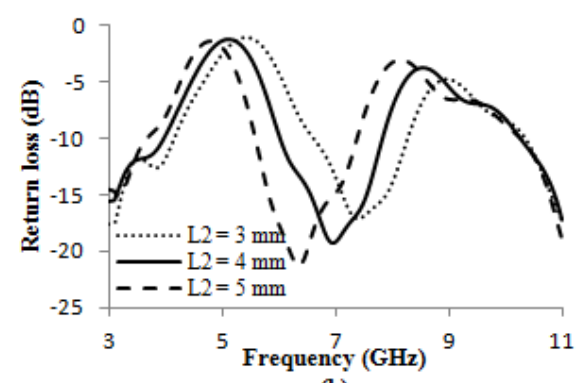

(b)

Fig. 5 Simulated return loss with variations in resonator structure length parameters (a) length L1, (b) length L2.

\section{B. Effect of Variation of length L2 on return loss}

The dimension of $\mathrm{L} 2$ is changed from $3 \mathrm{~mm}$ to $5 \mathrm{~mm}$ in a step of $1 \mathrm{~mm}$. The optimum value of L2 is 4 
$\mathrm{mm}$ where one notch band is from 4 to $6.2 \mathrm{GHz}$ and second notch band is from 7.6 to $10 \mathrm{GHz}$. Increasing the length $\mathrm{L} 2$ of resonator to $5 \mathrm{~mm}$, shifts the first notch band to 3.68 to 5.5 $\mathrm{GHz}$ and second band shifts to 7.4 to $10.28 \mathrm{GHz}$. Similarly decreasing the length $\mathrm{L} 1$ to $3 \mathrm{~mm}$ both notch bands gets shifted from 4.1 to $6.6 \mathrm{GHz}$ and 8.2 to $10.3 \mathrm{GHz}$. These variations are shown in fig. 5(b).

\section{Effect of Variation of length L3 on return loss}

The dimension of L3 is changed from $0.6 \mathrm{~mm}$ to $2.6 \mathrm{~mm}$ and optimum dimension observed to be $1.6 \mathrm{~mm}$. By varying the length L2 of resonator to $2.6 \mathrm{~mm}$, shifts the first notch band to 3.68 to $5.5 \mathrm{GHz}$ and second band to 7.4 to $10.28 \mathrm{GHz}$. Similarly decreasing the length L3 to $0.6 \mathrm{~mm}$ both notch bands gets shifted to 3.9 to $5.9 \mathrm{GHz}$ and 7.5 to $10.1 \mathrm{GHz}$. These variations are shown in fig. 5(c).

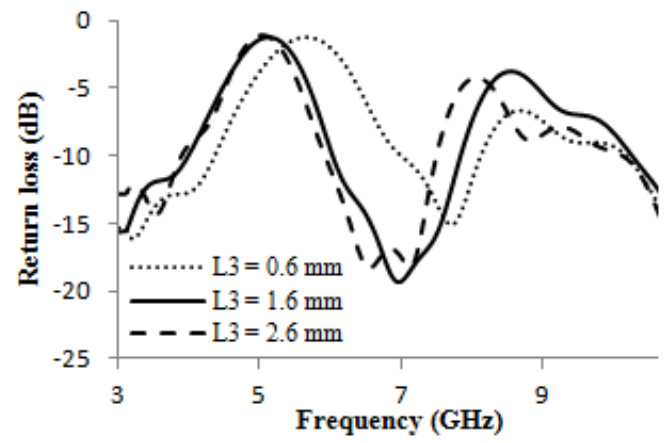

(c)

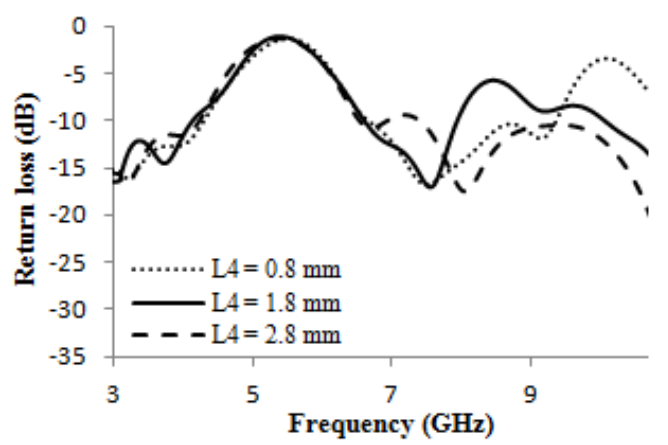

(d)

Fig. 5 Simulated return loss with variations in resonator structure length parameters (c) length L3, (d) length L4.

\section{Effect of Variation of length L4 on return loss}

The optimum value of L4 is $1.8 \mathrm{~mm}$ and it is varied from $0.8 \mathrm{~mm}$ to $2.8 \mathrm{~mm}$. There is slight shift in the first notch band when length L4 is varied. Varying the length L4 of resonator to $2.8 \mathrm{~mm}$ or $0.8 \mathrm{~mm}$, shifts the notch band to 4.3 to $6.6 \mathrm{GHz}$. These variations are shown in fig. 5(d).

\section{E. Effect of Variation of length L5 on return loss}

The optimum value of L5 is $1 \mathrm{~mm}$ and by varying the lengths from $0.5 \mathrm{~mm}$ to $2 \mathrm{~mm}$ no shift is observed in the first notch band. Second notch band is shifted to $9.4 \mathrm{GHz}$ onwards and $10 \mathrm{GHz}$ onwards when length is decreased to $0.5 \mathrm{~mm}$ and increased to $2 \mathrm{~mm}$ respectively as shown in the fig. 5(e).

\section{F. Effect of Variation of length L6 on return loss}

Varying optimum value of L6 does not show visible shift in the second notch band and is shown in the fig. 5(f). By decreasing length L6 to $3.8 \mathrm{~mm}$ shifts the lower notch band to $3.9-6.2 \mathrm{GHz}$ and by increasing L6 length to $5.8 \mathrm{~mm}$ shifts the notch band to $3.8-5.8 \mathrm{GHz}$. It is observed that by shifting resonating structure parameters of the $\mathrm{E}$ molded resonator, the bandwidth and center frequency of the rejected band can be adjusted.

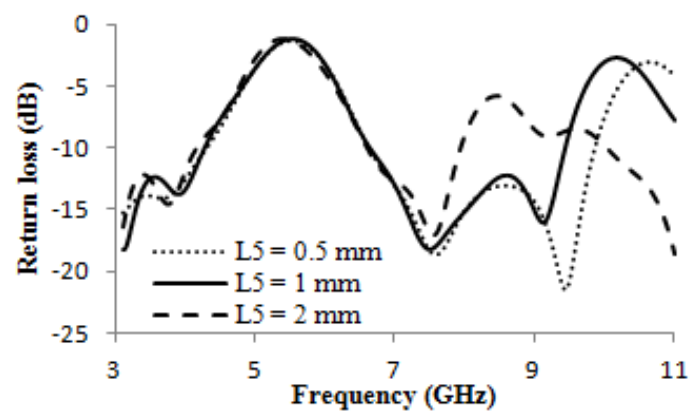

(e)

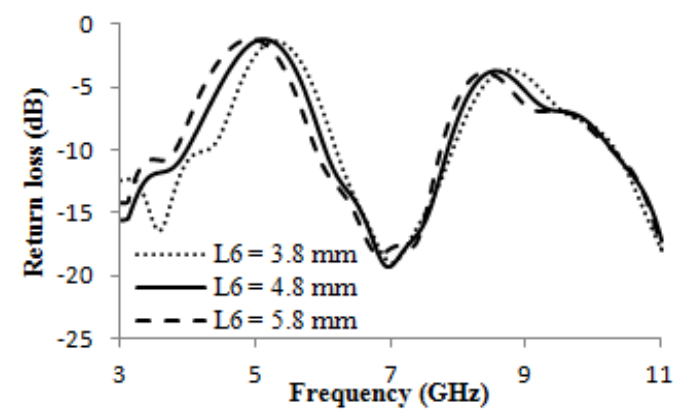

(f)

Fig. 5 Simulated return loss with variations in resonator structure length parameters (e) length L5, (f) length L6.

\section{G. Effect of Variation of width on return loss}

The width $W$ is varied from $0.3 \mathrm{~mm}$ to $0.7 \mathrm{~mm}$ with a step of $0.2 \mathrm{~mm}$. The width of resonators has less significant effect on the notch frequency as length has, and increase in the width affects lower notch band only. Increasing the width of the resonator to from $0.3 \mathrm{~m}$ to $0.5 \mathrm{~mm}$ shifts the lower notch band to $3.6-6 \mathrm{GHz}$ without affecting upper notch band significantly. Further increasing the width to $0.7 \mathrm{~mm}$ shifts the lower notch band to $3.9-6 \mathrm{GHz}$. The return loss characteristic with variations of width of $E$ shaped structures is shown in Fig. 5(g).

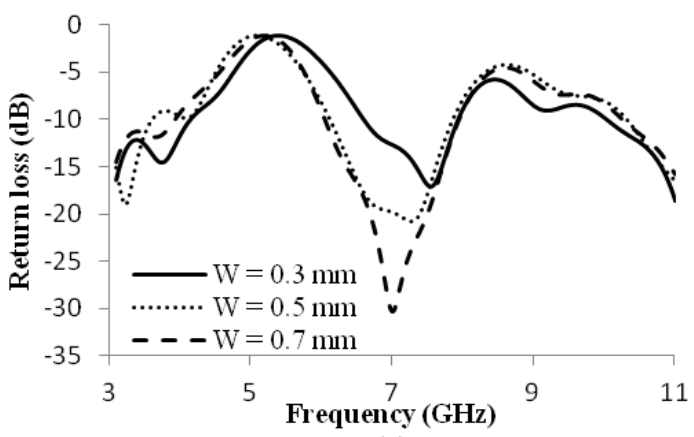

(g)

Fig. 5(g) Simulated return loss with variations in width of resonating structure.

\section{UWB ANTENNA WITH}




\section{RECONFIGURABLE NOTCH BAND CHARACTERISTICS}

The above designed structure is made notch band reconfigurable by employing two RF switches as shown in fig. 6 . The different views of the resonating structure are shown in the fig. 7(a-b). Fig. 7(a) presents the resonating structure when switch is ' $\mathrm{ON}$ ' and fig. 7(b) shows when switch is 'OFF'. These switches control the notch bands configuration in the UWB antenna. Two SPST RF switches (AMT2551011) with high isolation $40 \mathrm{~dB}(\mathrm{~min})$ are used and are biased as per the requirement [15]. Four different conditions are obtained by varying RF switch states which reconfigures resonator's shape. Table 2 shows different states of RF switch and corresponding configuration of resonating structure.

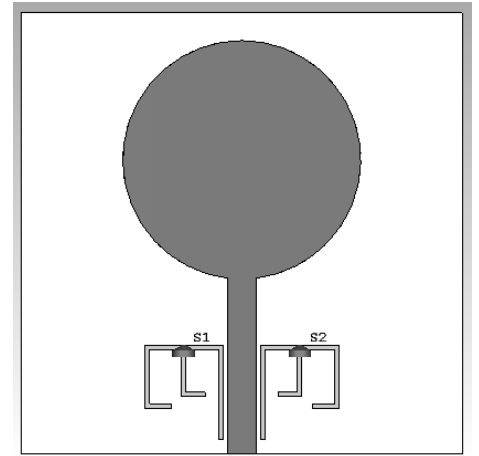

Fig. 6 Proposed UWB Antenna Structure with switches.
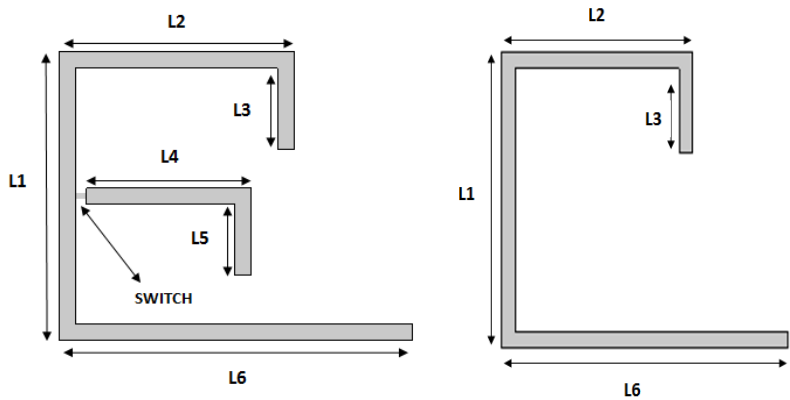

Fig. 7 Parameters of Reconfigurable (a) modified E shaped structure when switch is $\mathrm{ON}$, (b) modified $\mathrm{C}$ shaped structure when switch is OFF.

\section{RESULT AND DISCUSSIONS}

For the return loss measurements we are using KEYSIGHT E5063A vector network analyzer. Fig. 8 show the picture of fabricated antenna in which two SPST RF switches (AMT2551011) are used to achieve reconfigurability. Figs. 9(a-c) show the simulated and measured return loss plots for different switch states. If switches ( $S 1$ and $S 2)$ are in ON state, E shaped resonators are configured on each side of microstrip feedline measured return loss gives notch bands 4.1 to 5.8 $\mathrm{GHz}$ and 8.4 to $10.7 \mathrm{GHz}$ shown in the fig. 10(a). When one RF switch is in ON state and other in OFF state, one E shape and other is $\mathrm{C}$ shape resonators are configured on both sides of the feedline which create notch bands and the measured notch bands are 3.9 to $5.7 \mathrm{GHz}$ and 7.7 to $9.1 \mathrm{GHz}$ as shown in the fig. 9(b). When both RF switches are in OFF state, C shaped resonators are reconfigured with feedline creating a single notch band measured from 3.9 to $5.7 \mathrm{GHz}$ as shown in the fig. 9(c). Table 3 shows the operation of antenna for

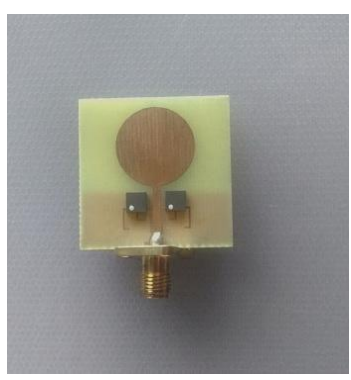

Fig. 8. Picture of fabricated antenna.

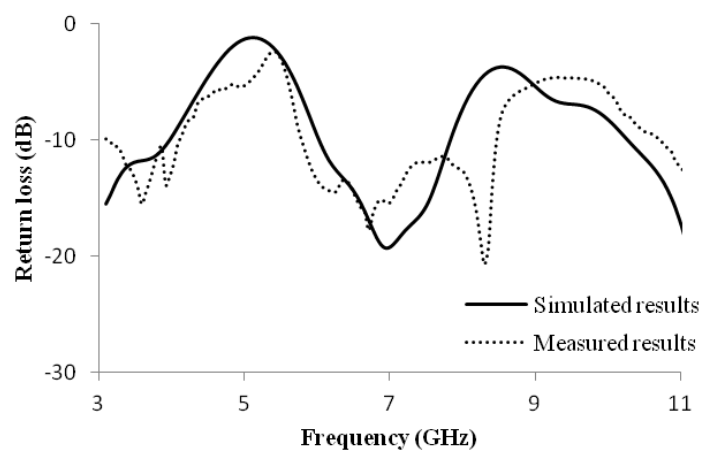

Fig. 9(a) Simulated and measured return loss when both switches are on.

different $\mathrm{ON}$ and $\mathrm{OFF}$ states of switches. To understand the phenomenon of tunable notch frequencies of the designed UWB antenna, the surface current distribution at the resonating structures and the feedline of circular patch antenna at notching frequencies is observed. At low frequencies current is mainly concentrated around the resonating structures and in the opposite direction which leads to attenuation. Similarly at high frequencies current distribution is denser on resonating structures which leads to desired attenuation.

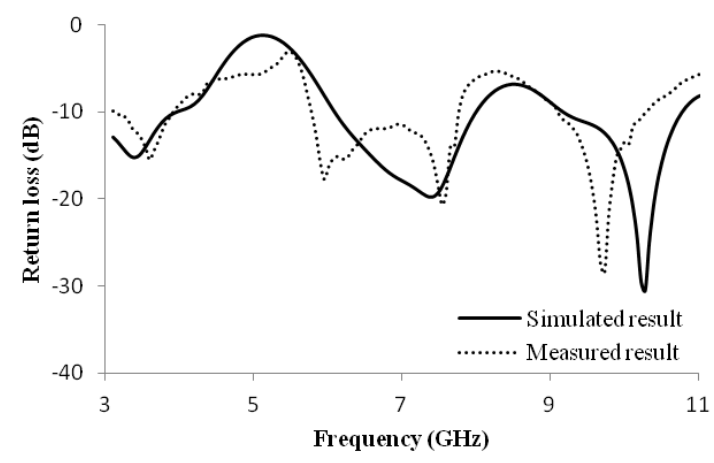

Fig. 9(b) Simulated and measured return loss when one switch is on and other is off.

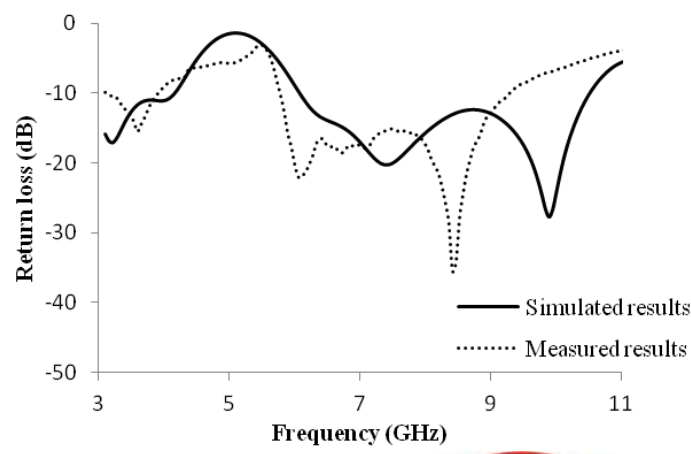

Fig. 9(c) Simulated and measured results when both switches are off. 
Table 2 Different RF switching states and resonators shape.

\begin{tabular}{cccc}
\hline \hline \multicolumn{2}{c}{ RF Switching states } & & \multicolumn{2}{c}{ Resonators configuration } \\
\hline Switch 1 & Switch 2 & Shape of Resonator 1 & Shape of Resonator 2 \\
\hline OFF & OFF & Modified C shape & Modified C Shape \\
OFF & ON & Modified C shape & Modified E shape \\
ON & OFF & Modified E shape & Modified C shape \\
ON & ON & Modified E shape & Modified E shape \\
\hline \hline
\end{tabular}

Table 3 Antenna operation for different on and off states of switches

\begin{tabular}{c} 
Antenna operations \\
\hline UWB coverage with dual notch band in WLAN, WiMAX, C-band and Satellite X band $\quad$ S1 and S2 both are on \\
UWB coverage with dual notch band in WLAN, WiMAX, C-band and meteorological S1 is ON and S2 is OFF or S1 is OFF and S2 is \\
satellites
\end{tabular}

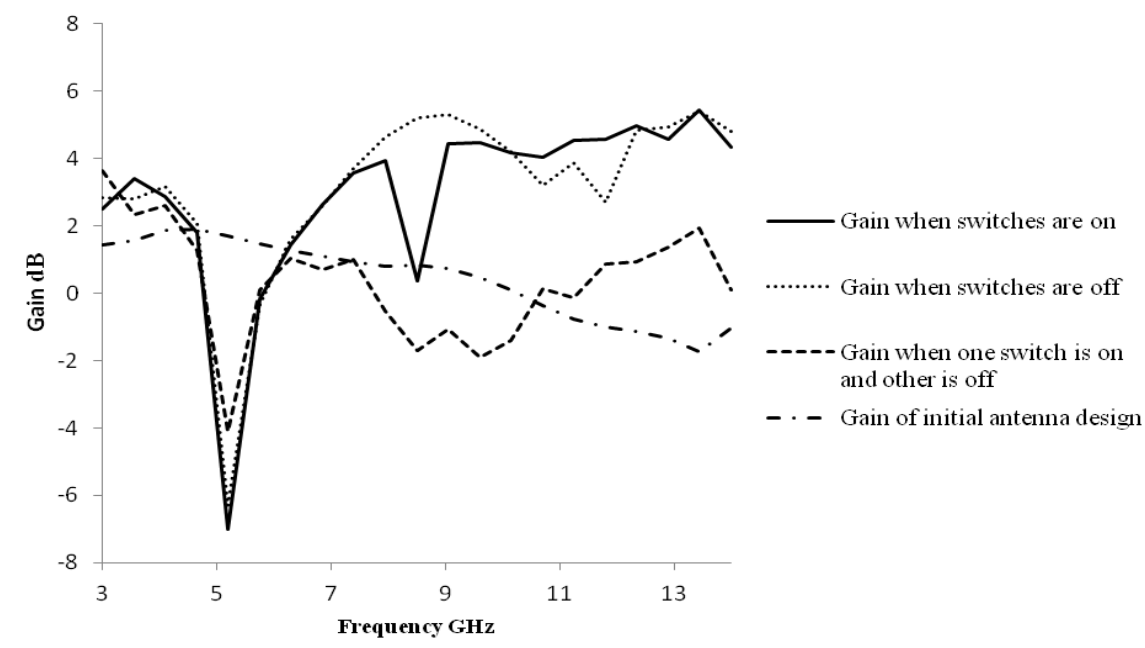

Fig. 10 Simulated maximum gain comparison of initial antenna design, proposed antenna when both switches are on, when both switches are off and when one switch is on and other is off.

Fig. 10 displays peak gains of basic UWB antenna and proposed antenna with all OFF and ON states of the switches. Gain varies between 2 to $5.5 \mathrm{~dB}$ at different operating frequencies. The designed UWB reconfigurable antenna with optimized dimensions is fabricated and tested. Fig. 11 shows the measured and simulated radiation patterns in the E-plane and H-plane when both switches are 'off' at $3.2 \mathrm{GHz}, 7.3 \mathrm{GHz}$ and $9.8 \mathrm{GHz}$. It is evident that radiation patterns in the $\mathrm{H}$-plane are nearly omnidirectional and radiation pattern in the E-plane is eight shaped. Fig. 12 shows the measured and simulated radiation pattern when both switches are 'on' at 5.1 $\mathrm{GHz}, 6.8 \mathrm{GHz}$ and $8.4 \mathrm{GHz}$. It is observed that radiation patterns in the $\mathrm{H}$ plane are of circular shape and E-plane radiation pattern are of the shape of a cardioid.

\section{CONCLUSION}

An ultra-wideband antenna with reconfigurable notches has been designed in this paper. The designed antenna has wide bandwidth impedance matching in range $3.1 \mathrm{GHz}$ to 10.6 GHz. To achieve reconfiguration, first the switches are biased to ON state, due to this 'modified E shaped' resonators are configured on both sides of feedline of circular patch antenna which results in the UWB antenna radiating from 3.1 to $10.6 \mathrm{GHz}$ with 4 to $6.2 \mathrm{GHz}$ and 7.6 to $10 \mathrm{GHz}$ band-rejection characteristics. When one switch is $\mathrm{ON}$ and other switch is OFF; one 'modified E shape' and one 'modified $\mathrm{C}$ shape' resonator are reconfigured and thus band rejected from 4 to $6.1 \mathrm{GHz}$ and 8 to $9.1 \mathrm{GHz}$. After that the switches are biased to OFF state; the 'modified $\mathrm{E}$ shape' resonators are reconfigured to 'modified $\mathrm{C}$ shape' and thus band rejection from 4 to $6.2 \mathrm{GHz}$ is obtained. The frequencies for WLAN, WiMAX and X-band satellite communication applications respectively are rejected. By adjusting the length of modified $\mathrm{E}$ and $\mathrm{C}$ shaped resonators, the center frequency of the notch band can be altered which can be used to avert the interferences. 


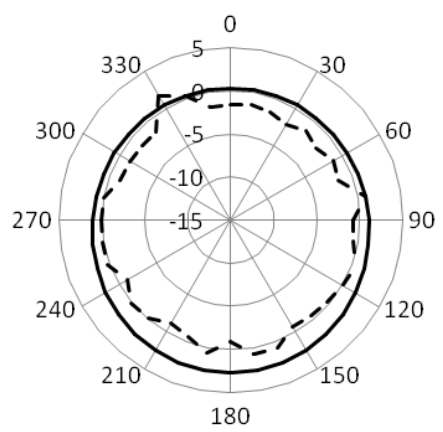

$\mathrm{H}$ plane at $3.2 \mathrm{GHz}$

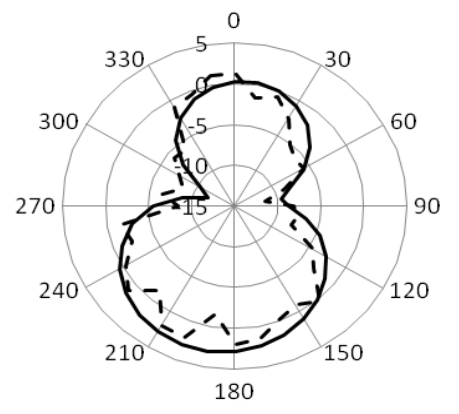

E plane at $3.2 \mathrm{GHz}$

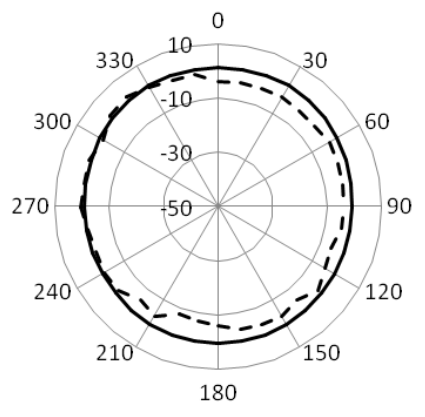

$\mathrm{H}$ plane at $7.3 \mathrm{GHz}$

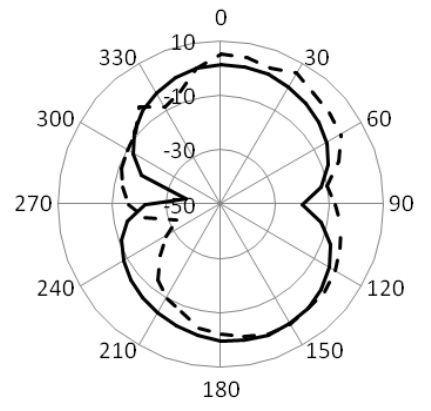

E plane at $7.3 \mathrm{GHz}$

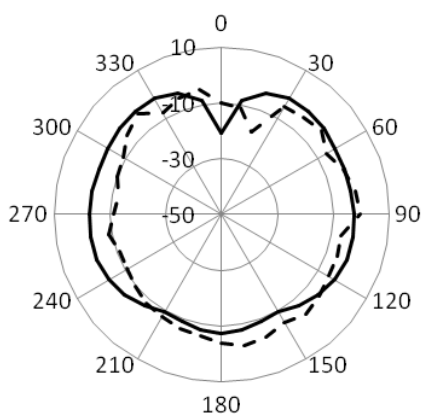

$\mathrm{H}$ plane at $9.8 \mathrm{GHz}$

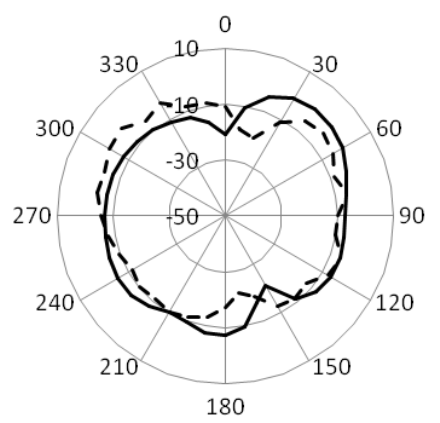

E plane at $9.8 \mathrm{GHz}$

Simulated results

- - - Measured results

Fig. 11 Measured and simulated results of radiation pattern of $\mathrm{E}, \mathrm{H}$ plane when switches are $\mathrm{OFF}$ at frequencies $3.2 \mathrm{GHz}, 7.3 \mathrm{GHz}$ and 9.8 $\mathrm{GHz}$.

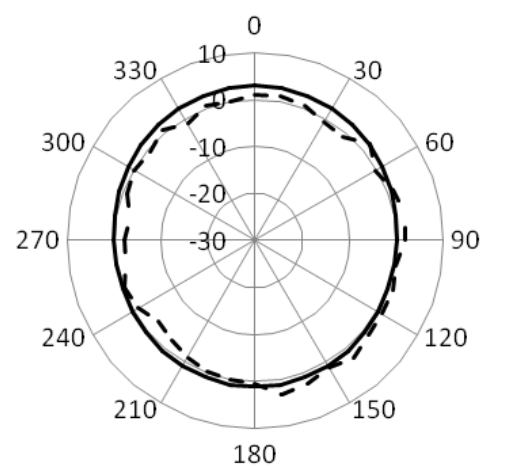

$\mathrm{H}$ plane at $5.1 \mathrm{GHz}$

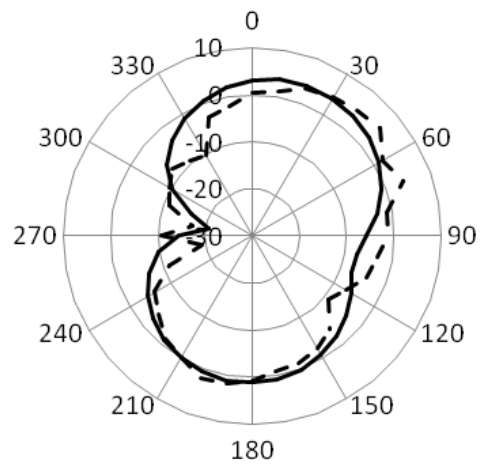

E plane at $5.1 \mathrm{GHz}$

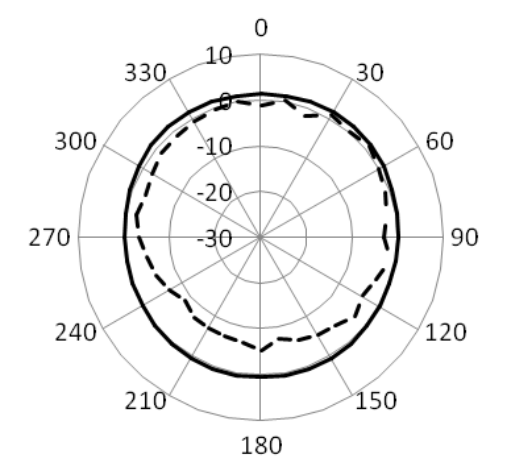

$\mathrm{H}$ plane at $6.8 \mathrm{GHz}$

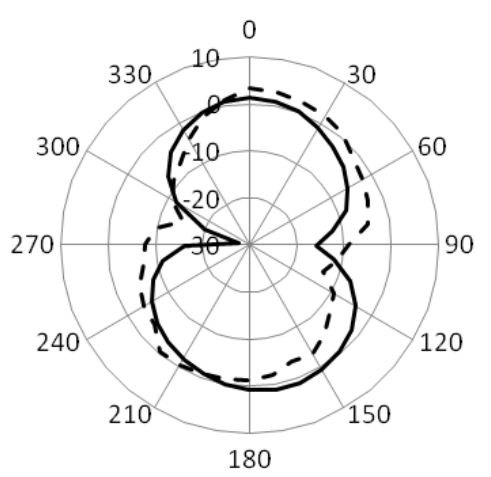

E plane at $6.8 \mathrm{GHz}$

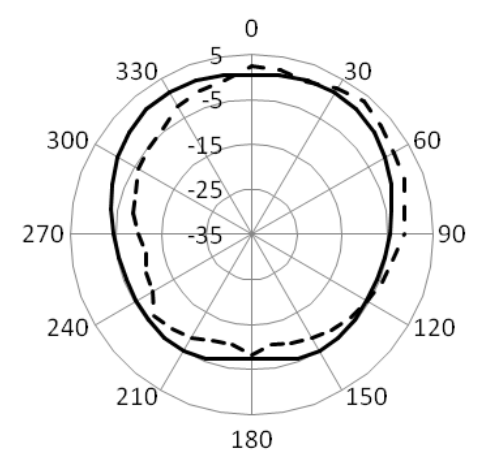

$\mathrm{H}$ plane at $8.4 \mathrm{GHz}$

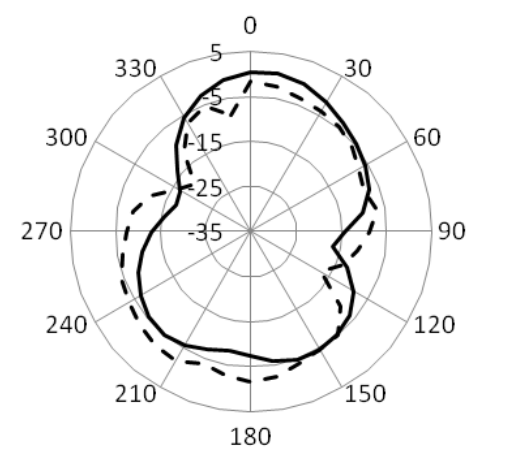

E plane at $8.4 \mathrm{GHz}$

Simulated results

- - - Measured results

Fig. 12 Measured and simulated results of radiation pattern of E, $\mathrm{H}$ plane when switches are $\mathrm{ON}$ at frequencies $5.1 \mathrm{GHz}, 6.8 \mathrm{GHz}$ and 8.4 $\mathrm{GHz}$.

\section{REFERENCES}

[1]US Federal Communications Commission, et al., "FCC revision of part 15 of the commission's rules regarding ultra-wideband transmission systems: First report and order," Technical Report, Feb. 2002.
[2] M. Ojaroudi, N. Ojaroudi, "Novel design of dual band-notched monopole antenna with bandwidth enhancement for UWB applications", IEEE Antennas Wirel. 
Propag. Lett., vol. 12, 2013, pp. 698-701.

[3]L.Y. Cai, "Compact printed ultra-wideband antennas with band-notched characteristics," in Electronics Letters , vol. 46, no. 12, 2010, pp. 817-819.

[4]R. Zaker, C. Ghobadi, and J. Nourinia, "Bandwidth enhancement of novel compact single and dual band-notched printed monopole antenna with a pair of L-shaped slots," IEEE Trans. Antennas Propag., vol. 57, no. 12, Dec. 2009, pp. 3978-3983.

[5]Nikolaou, S., Kingsley, N.D., Ponchak, G.E., et al., "UWB elliptical monopoles with a reconfigurable band notch using MEMS switches actuated without bias lines", IEEE Trans. Antennas Propagation., vol. 57, no. 8, 2009, pp. 2242-2251.

[6]Homayoon Oraizi, "Frequency- and time-domain analysis of a novel UWB reconfigurable microstrip slot antenna with switchable notched bands", IET Microwaves, Antennas \& Propagation, vol. 11, no. 8, May 2017 , pp. 1127-1132.

[7]A. Tariq, H. Ghafouri-Shiraz, "Frequency-reconfigurable monopole antennas", IEEE Trans. Antennas Propag., vol. 60, no. 1, pp. 44-50, 2012.

[8]D. E Anagnostou, "Reconfigurable UWB antenna with RF-MEMS for on-demand WLAN rejection," IEEE Trans. Antennas Propagation, vol. 62, no. 2, Feb. 2014, pp. 602-608.

[9]B. Badamchi, J. Nourinia, C. Ghobadi, and A. V. Shahmirzadi, "Design of compact reconfigurable ultra-wideband slot antenna with switchable single/dual band notch functions," IET Microwave Antennas Propagation, Vol. 8, No. 8, Nov. 2013, pp. 541-548.

[10] W. A. E. Ali, and R. M. A. Moniem, "Frequency reconfigurable triple band-notched ultra-wideband antenna with compact size," Progress In Electromagnetics Research C, Vol. 73, Apr. 2017, pp. $37-46$.

[11] K. C. Gupta, R. Garg, I. J. Bhal, and P. Bhartia, Microstrip Lines and Slotlines, 2nd Edition,10-15, Artech House, 1996.

[12] Abhishek Viswanathan, Rajasi Desai, "Applying Partial-Ground Technique to Enhance Bandwidth of a UWB Circular Microstrip Patch Antenna," International Journal of Scientific \& Engineering Research, Vol. 5, Issue 10, Oct. 2014.

[13] A. Valizade, Ch. Ghobadi, J. Nourinia, N. Ojaroudi, M. Ojaroudi, "Band-notch slot antenna with enhanced bandwidth by using $\Omega$-shaped strips protruded inside rectangular slots for UWB applications", Applied Computer Electromagnetics Society (ACES) J., vol. 27, no. 10, 2012, pp. 816-822.

[14] S. Nikolaou, N.D. Kingsley, G.E. Ponchak, "UWB elliptical monopoles with a reconfigurable band notch using MEMS switches actuated without bias lines', IEEE Transaction Antenna Propagation, vol. 57, no. 8, 2009, pp. 2242-2251.

[15] Datasheet http://astramtl.com/admin/uploads/switches/datasheets/1360083 817_2551011.pdf

\section{AUTHORS PROFILE}

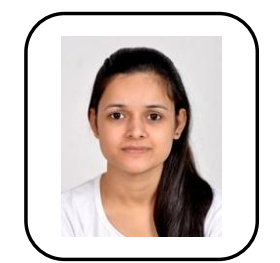

Ritika Sharma received a B. tech degree in ECE in 2014 from IET Bhaddal, Ropar and completed M.E. degree from Thapar Institute of Engineering and technology, Patiala in 2018. Presently she is pursuing PhD from Thapar Institute of Engineering and technology, Patiala. Her research mainly includes microstrip patch antenna and VLSI interconnects

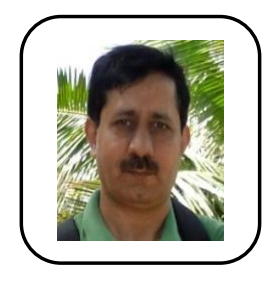

Rajesh Khanna received a B.Sc. (Engg.) degree in ECE in 1988 from REC, Kurukshetra and M.E. degree in 1998 from IISc., Bangalore. He was with Hartron R\&D center till 1993. Until 1999, he was in AIR as Assistant Station Engineer. Presently, he is working as Professor in the ECED at Thapar Patiala. He has published 80 nstitute of Engineering and Technology, 